\title{
Manipulating osa-MIR156f Expression by D18 Promoter to Regulate Plant Architecture and Yield Traits both in Seasonal and Ratooning Rice
}

Qing Liu ${ }^{1 \dagger}$, Yi Su ${ }^{1,2+}$, Yunhua Zhu ${ }^{3}$, Keqin Peng ${ }^{1}$, Bin Hong ${ }^{1}$, Ruozhong Wang ${ }^{1,2}$, Mahmoud Gaballah ${ }^{4}$ and Langtao Xiao ${ }^{1,2^{*}}$

\begin{abstract}
Background: Rice (Oryza sativa L.) feeds more than half of the world's population. Ratooning rice is an economical alternative to the second seasonal rice, thus increasing the yield of ratooning rice is highly important.

Results: Here we report an applicable transgenic line constructed through the manipulation of osa-MIR156f expression in rice shoot using the OsGA30x2 (D18) promoter. In seasonal rice, the D18-11 transgenic line showed moderate height and more effective tillers with normal panicle. In ratooning rice, axillary buds outgrew from the basal node of the D18-11 transgenic line before the harvest of seasonal rice. More effective tillers produced by the outgrowth of axillary buds contributed to the plant architecture improvement and yield increase. Additionally, it was found that osa-miR156f down-regulated the expression of tillering regulators, such as TEOSINTE BRANCHED1 (TB1) and LAX PANICLE 1 (LAX1). The expression of DWARF10, DWARF27 and DWARF53, three genes being involved in the biosynthesis and signaling of strigolactone (SL), decreased in the stem of the D18-11 transgenic line.

Conclusion: Our results indicated that the manipulation of osa-MIR156f expression may have application significance in rice genetic breeding. This study developed a novel strategy to regulate plant architecture and grain yield potential both in the seasonal and ratooning rice.
\end{abstract}

Keywords: Seasonal rice, Ratooning rice, Osa-MIR156f, Plant architecture, Grain yield

\section{Background}

Rice (Oryza sativa L.) is the staple food of more than half of the world's population which is expected to reach 9 billion by the year of 2050 . To meet the needs of the projected population, at least a $40 \%$ improvement of crop yield will be needed by 2025 [1, 2]. Therefore, increasing crop yield is one of the most important goals in modern agriculture. The ideal plant architecture for rice, i.e. the phenotype of moderate height, enough effective tillers, large panicle and robust stems/roots, is crucial for high yield $[3,4]$. In the

\footnotetext{
* Correspondence: Itxiao@hunau.edu.cn

${ }^{+}$Qing Liu and Yi Su contributed equally to this work.

${ }^{1}$ Hunan Provincial Key Laboratory of Phytohormones and Growth Development, Hunan Agricultural University, Changsha 410128, China ${ }^{2}$ Southern Regional Collaborative Innovation Center for Grain and Oil Crops in China, Hunan Agricultural University, Changsha 410128, China Full list of author information is available at the end of the article
}

past two decades, various genes regulating rice plant architecture related traits have been identified. For example, Grain number 1a (Gn1a) [5] and ABERRANT PANICLE ORGANIZATION 1 (APO1) [6] regulate grain number. Grain Size 3 (GS3), Grain Weight 2 (GW2) and SQUAMOSA-PROMOTER BINDING LIKE 13 (SPL13) regulate grain size [7-10]. DENSE AND ERECT PANICLE 1 (DEP1), SMALL PANICLE (SPA) and LAX PANICLE 1 (LAX1) control panicle size [11, 12]. SPL14 promotes panicle branching and grain yield [13, 14]. TEOSINTE BRANCHED1 (TB1) regulates lateral branching and represses the outgrowth of axillary buds [15]. MONOCULM 1 (MOC1) controls rice branching and axillary meristem initiation [16]. ELONGATED UPPERMOST INTERNODE1 (EUI1), SEMI DWARF1 (SD1), SLENDER RICE1 (SLR1), GA-INSENSITIVE DWARF1 (GID1) and GID2, several 
genes being related to gibberellin (GA) biosynthesis/signaltransduction, jointly regulate plant height [17]. The successful identification of these genes involved in rice plant architecture regulation greatly promoted the elucidation of the underlying molecular mechanisms.

Strigolactones (SLs) regulate rice tiller development through interactions with tillering related genes. DWARF 53 (D53), the repressor of the SL signaling pathway, is able to directly interact with the N-terminal domains of miR156-controlled SPLs and represses the expression of TB1 [13, 18, 19]. SPL14 interacts with MADS57, which directly binds to the CArG motif of the DWARF14 (D14) promoter and suppresses $D 14$ transcription to control the outgrowth of axillary buds in rice [20]. LAX1 and Rice Leafy Homolog1 (RFL), being highly co-expressed with SPL7, SPL14, and SPL17, are down-regulated in the panicles of the osa-MIR156 overexpression line [11, 21, 22]. SPL14 is able to bind to the $L A X 1$ promoter, which implies that $L A X 1$ may also be directly regulated by SPL14 [23]. The expression of Rice TFL1/CEN homolog1 (RCN1) is suppressed by MADS34 [24, 25]. MADS34, SPL, LAX1 and $R F L$ are down-regulated in the $o s a-M I R 156 b$ and $o s a-$ MIR156h overexpression line [26].

Several studies focused on the important regulators for rice plant architecture. Among them, microRNAs show immense application potential in genetic breeding because of their flexible and precise regulation of tillering and panicle branching. miR156 targets SPLs and regulates plant growth and development [27]. Furthermore, miR156 and SPLs are involved in plant embryogenesis [28], shoot maturation [29], flowering control [30], phase change [27, 3134], biomass production [31, 35], panicle cell death [36], and crown root development [37]. In rice, ten osa-MIR156 genes produce five mature osa-miR156 sequences and the overexpression of osa-MIR156 produces more tillers [26]. SPL14 defines the plant architecture by decreasing tiller number and increasing plant height/panicle branch number, thus shows great potential for genetic breeding [13, 14]. Interestingly, SPL14 mRNA contains a recognition site for miR156 and its spatiotemporal expression is strictly controlled by miR156. Our previous study also found that a high level of osa-MIR156f in rice caused a dwarf and multi-tillering phenotype [38]. Additional regulatory networks, such as the miR529/SPL, miR172/AP2 and $\mathrm{miR} 156 / \mathrm{miR} 159$ pathways, also influence rice tillering and panicle branching [23, 34, 39]. Moreover, SLs suppress shoot branching by inhibiting the outgrowth of axillary buds through the D53 repressor signaling pathway. D53 interacts with IDEAL PLANT ARCHITECTURE1 (IPA1) in vivo and in vitro to suppress the transcriptional activation activity of SPL14. SPL14 functions as a direct downstream component of D53 in regulating tiller number and SL-induced gene expression. SPL14 may directly bind to the D53 promoter and plays a critical role in the feedback regulation of SL-induced D53 expression [40]. Although the miR156/SPL14 pathway is important in rice tillering, constitutive overexpression lines of osa-MIR156 produce a severely defective phenotype, with the tillers and panicles being totally ineffective.

Ratooning rice is an economical alternative to the second seasonal rice in subtropical and temperate zones, where the light and temperature are not enough for double cropping cultivation [41]. Compared to the second seasonal rice cultivation, ratooning rice may significantly decrease the production costs by reducing the input of labor force, fertilizer, pesticides and herbicides [42]. Furthermore, ratooning rice results in better grain quality and less field pollution [42, 43]. Thus the research of ratooning rice is of great significance.

Ratooning rice develops from the regenerated tillers on the stubble left behind the first seasonal rice harvest. Meanwhile, the different origin points of ratoon tillers on the main-crop stubble show different yield potential since ratoon panicles decrease in size as the point of origin changes acropetally (from the base upward) [41]. Similar to the first seasonal rice, the early ratoon tillers originated from the internodes are the main contributors for ratooning rice yield. In fact, compared to seasonal rice, grain yield in ratooning rice is more dependent on the fertile tiller number per plant and fertile grain number per panicle [44].

Guiding precise gene expression in plant tissues using tissue specific promoters is feasible to reduce the negative effects of overexpression. Recently, it had reported a modification in the expression of IPA1 increases disease resistance against bacterial blight and substantially increases the yield potential in rice by that using the bacterium-inducible promoter of OsHEN1 [45]. In this study, osa-MIR156 $f$ was specifically expressed in the rice stem under the control of the promoter of a GA biosynthesis gene, GA3ox2 (D18) $[46,47]$. Compared to the wild type, the transgenic line presented moderate height, more effective tillers, and increased grain yield both in seasonal and ratooning rice. The manipulation of osa-MIR156 $f$ expression may have application significance in rice genetic breeding. Moreover, it was hypothesized that miR156f may control tillering through manipulating the spatiotemporal expression of OsTB1, OsLAX1 and OsD53.

\section{Results \\ Expression Pattern of osa-MIR156f in Rice}

Two copies of osa-MIR156 $f$ are adjacently located in two large repeat fragments on chromosome 8 of Nipponbare. Pre-miR156f can form a typical hairpin, and the mature osa-miR156f is a $20 \mathrm{nt}$ fragment (Fig. 1a). In previous study, we have identified that osa-MIR156f plays important roles in rice tillering and plant architecture [38]. To further understand the detailed function of osa-MIR156f, we obtained 21 independent transgenic lines by harboring 

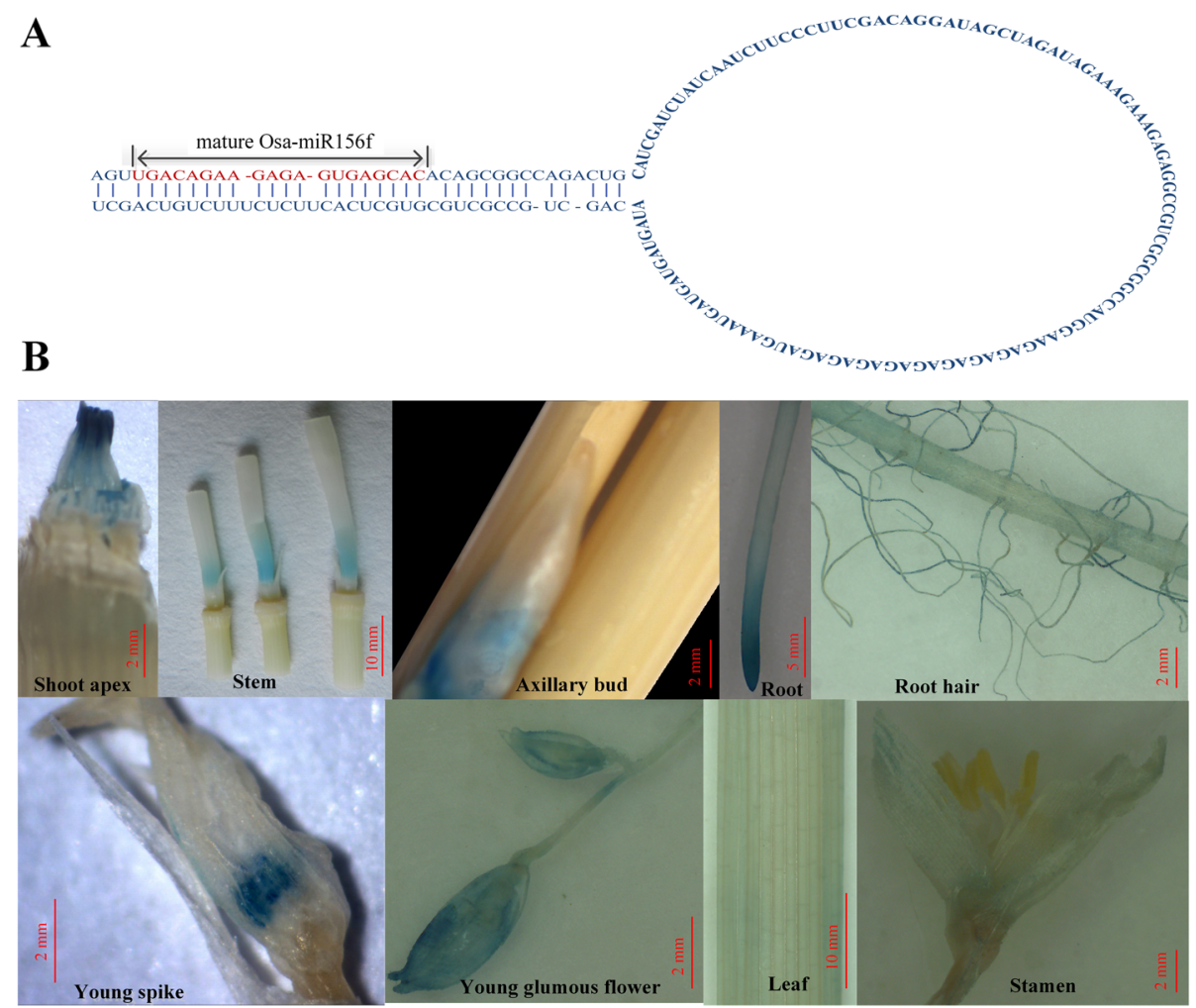

C

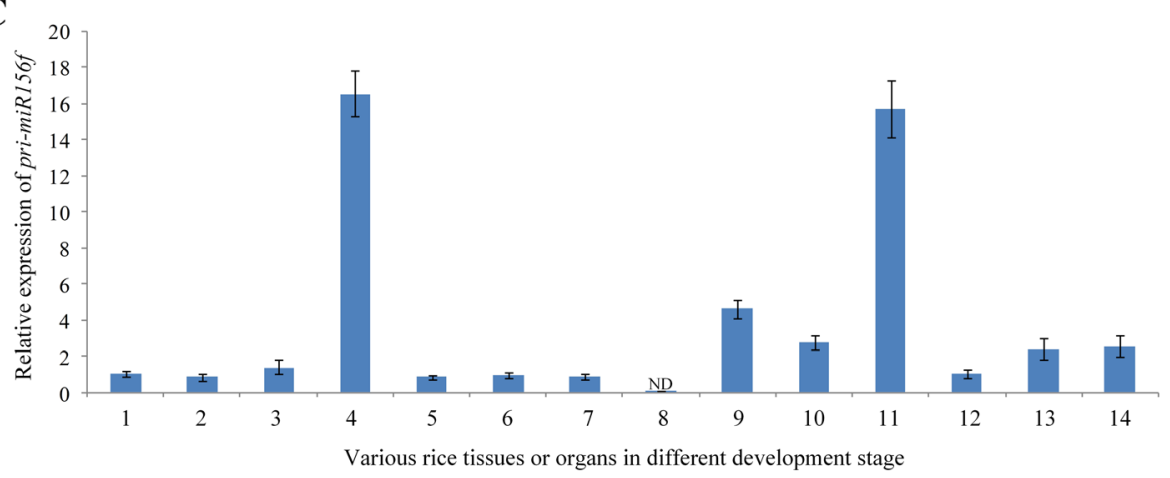

Fig. 1 Expression pattern of osa-MIR156f. a The typical hairpin structure of pre-miR156f and the $20 \mathrm{nt}$ of the mature miR156f. b Localization of GUS activity driven by the osa-MIR156f native promoter in different tissues. The sampling dates for tissues were as follows: shoot apex at the 3week-old seedling stage, stem at the flowering stage, axillary bud at the heading stage, root at the 3-week-old seedling stage, root hair at the tillering stage, young spike at the heading stage, young glumous flower at the panicle booting stage, leaf segment at the heading stage and stamen at the flowering stage. c Relative expression of pri-miR156f in various rice tissues or organs: 1, leaf lamina at tillering stage; 2 , leaf sheath at the tillering stage; 3 , shoot apex at the tillering stage; 4 , stem segment (about $0.5 \mathrm{~cm}$ ) above the node at the flowering stage; 5 , axillary bud at the tillering stage; 6 , young spike at the heading stage; 7 , young glumous flower at the heading stage; 8 , stamen (ND: not detected); 9 , basal node at the heading stage; 10, root tip (about $0.5 \mathrm{~cm}$ ) at the heading stage; 11, 3-week-old leaf; 12, 3-week-old shoot; 13, 3-week-old basal node; 14, 3-week-old root. The $\Delta \Delta \mathrm{Ct}$ method was used to calculate the relative gene expression. Error bars indicated the standard deviation (SD). Three independent biological replicates were analyzed $(n=3)$

osa-MIR156f pro::GUS ( $\beta$-glucuronidase) fusions from Nipponbare and observed the expression pattern of osaMIR156f during rice growth and development. Histochemical analysis showed that the GUS expression was spatiotemporally restricted. High GUS expression was found in the young tissues, such as the shoot apex, axillary bud, young spike and young glumous flower (Fig. 1b).
Strong GUS activity was associated with elongating zones in the stem (Fig. 1b). The GUS staining was also detected in root hair, root tip, young spike and glumous flower (Fig. 1b). In the axillary tiller buds, the GUS staining only appeared in bud on outgrowable unelongated basal internodes, but not in dormant buds on elongated internode (Fig. 1b, Additional file 1: Supplemental file S4). In 
addition, GUS expression was detected in leaf lamina at tillering stage and flag leaf at heading stage (Additional file 1: Supplemental file S4 D and E). To further analyze the expression pattern of osa-MIR156f, the level of primiR156 $f$ was relatively quantified by RT-qPCR in young tissues of the wild type at different developmental stages. The expression of osa-MIR156 $f$ was detected in young tissues except stamen (Fig. 1c). Young stem segment (about $0.5 \mathrm{~cm}$ ) above the node at the tillering stage, basal node at heading stage, and 3-week-old leaf showed higher level of pri-miR156f than other young tissues (Fig. 1c).

\section{Manipulation of osa-MIR156f Expression in Rice Shoot by the D18 Promoter}

The constitutive overexpression of osa-MIR156 in rice may sharply downregulate the level of SPL14, and then bring about severe defects in tillering and panicle development [23, 26] (Fig. 2a). In the current study, we applied different promoters to drive the expression of osa-MIR156f in rice and observed the subsequent effects on rice plant architecture respectively. In our previous research, osa-MIR156f was constitutively overexpressed through the Ubiquitin1 promoter in Nipponbare and more than 35 independent lines with similar architecture were screened [38]. Among them, U-16 showed severely defective phenotypes, such as dwarf architecture, distinct reduction in filled grain numbers and an obvious increase in ineffective tillers (Fig. 2a). These defects in the rice grain of the UBQpro::osa-MIR156f lines indicated that the high osa-miR156 may be deleterious to the reproductive development.

Previous researches indicated that expression of $D 18$ was observed around the shoot apex [48]. OsGA2ox1 ectopic expression in shoots by the promoter of $D 18$ resulted in a semi-dwarf phenotype with normal flower and grain development [46]. In order to reduce the negative effects of overexpressed osa-MIR156f on rice growth and development, the D18 promoter was employed to drive the expression of osa-MIR156 $f$ in rice. We screened 30 independent lines with similar phenotype in plant architecture from 77 candidate transgenic lines. Comparing to UBQpro::osa-MIR156f transformants and WT, most of the D18pro::osa-MIR156f lines did not show defective phenotypes (Fig. 2a, Additional file 1: Supplemental file S5). Therefore, we selected a typical D18pro::osa-MIR156f transgenic line (named D18-11) as the material in this study. D18-11 produced more effective tillers than the wild type. At the heading stage, gene expression analysis showed that the transcriptional levels of pri-miR156f in stems and basal nodes of D18-11 were higher than that of the wild type, but no differences were observed in the roots, leaves and panicles (Fig. 2b). The levels of osamiR156 and pri-miR156f were also examined in 3-weekold seedlings. Results showed that the pri-miR156f contents and mature osa-miR156 levels in different organs of
D18-11 were not always consistent (Fig. 2c, d). Although the pri-miR156f level in roots was increased compared to the wild type, osa-miR156 level was lower in D18-11 than that in the wild type. The level of pri-miR156f in leaves was down-regulated, but the osa-miR156 level was increased in D18-11 compared to the wild type. The level of pri-miR156f and osa-miR156 in the shoot was significantly up-regulated in D18-11 (Fig. 2c, d). These results indicated that the $D 18$ promoter may precisely manipulate the tissue-specific expression of osa-MIR156 $f$ in stem.

\section{D18pro::osa-MIR156f Rigorously Affected Tillering Related Gene Expression and SL Level}

osa-MIR156 $f$ was driven to express in the stem by the $D 18$ promoter to regulate rice tillering. To confirm the downstream regulators, some tillering and branching related genes were selected for further investigation by RT-qPCR at the tillering stage (Fig. 3). The target genes (including OsSPL3/7/13/14) of osa-miR156 were down-regulated in the stem of D18-11 (Fig. 3a, Additional file 1: Supplemental file S6). Previous research found that OsSPL13 positively regulates cell size in the grain hull, resulting in enhanced rice grain length [10]. However, no significant differences in grain size (including length, width and 1000-grain weight) were detected between D18-11 and the wild type although the expression of OsSPL13 was slightly down-regulated (Table 1, Fig. 4b). In addition, OsTB1 was slightly downregulated, and both the transcriptional levels of OsLAX1 and Rice OsRCN1 were significantly reduced $(P<0.05)$.

Interestingly, osa-MIR156f significantly affected the SL signaling and biosynthesis pathways. OsD14, OsDWARF10 (D10), OsDWARF27(D27), OsD53 and OsMADS57 were down-regulated in the stem of D18-11 (Fig. 3a). SL contents were significantly different at the 3-week-old seedling stage and stem elongation stage in D18-11 and the wild type. In 3-week-old seedlings, lower SL level was detected in shoots and roots of D18-11 in comparison to the wild type $(P<0.05)$ (Fig. 3b). SL content differences in leaves were not significant between D18-11 and the wild type. At the stem elongation stage (about 70 days after germination), SL in D18-11 stems was lower than that in the wild type $(P<0.05)$, but SL in D18-11 roots was significantly increased $(P<0.01)$ (Fig. 3c). These results indicated that osa-miR156 may affect SL synthesis or SL homeostasis in rice.

\section{D18pro::osa-MIR156f Demonstrated Improved Architecture Characteristics and Increased Rice Yield}

In this study, semi-dwarf transgenic rice plants (D1811) with more effective tillers were obtained (Fig. 4a-b). To further analyze the influence of osa-MIR156f on rice development, the morphological indexes and grain yield were investigated. At all investigated time points, the height and leaf length of the transformant U-16 were 

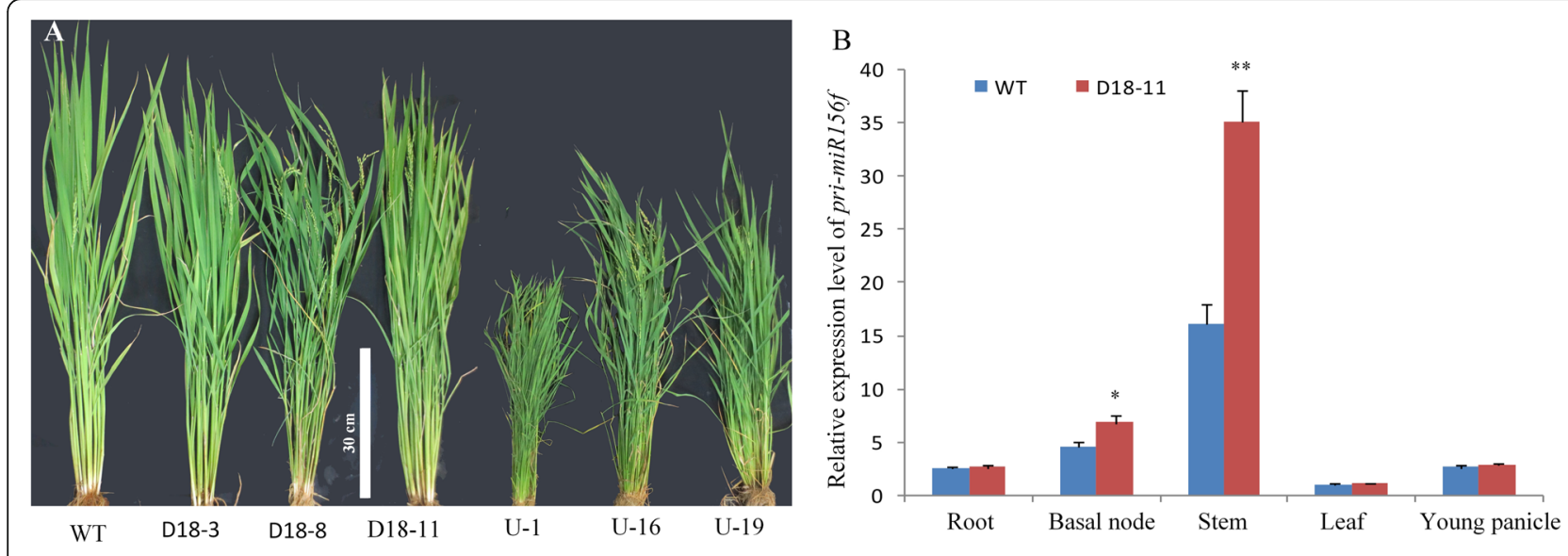

$\mathrm{C}$

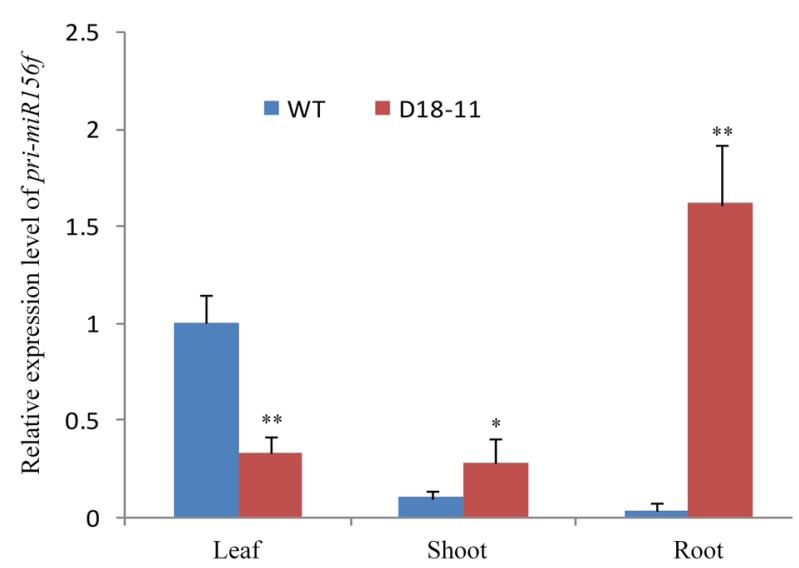

D

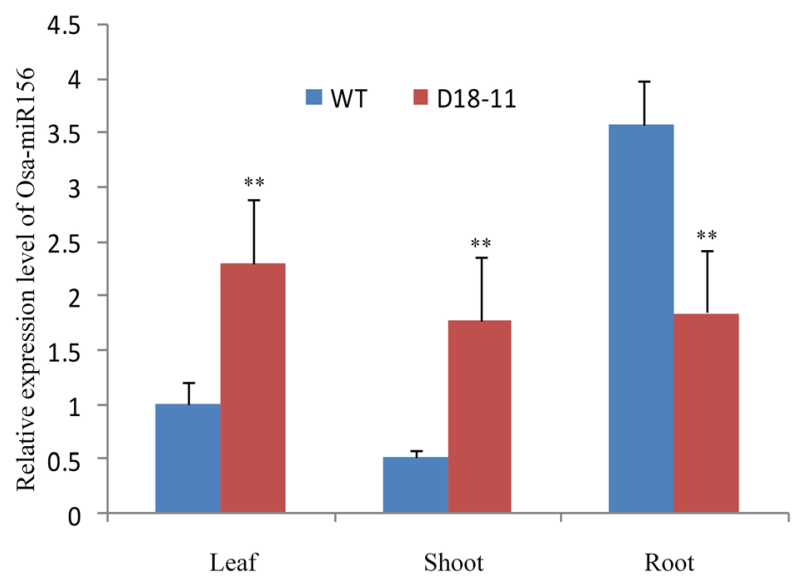

Fig. 2 Expression of osa-MIR156f in transgenic rice. a Phenotype of transgenic rice lines including three D18p::0sa-MIR156f lines (D18-3, D18-8 and D18-11) and three UBQpro::osa-MIR156f lines (U-1, U-16 and U-19). b Expression analysis of pri-miR156f in different tissues of D18-11 and the wild type (WT) rice at the heading stage. c Expression analysis of pri-miR156f in different tissues of D18-11 and the WT rice at 3-week-old seedling stage. $\mathbf{d}$ Mature osa-miR156 level in different tissues of D18-11 and WT rice at 3-week-old seedling stage. The $\Delta \Delta C t$ method was used to calculate the relative gene expression. Error bars indicated the standard deviation (SD). Three independent biological replicates were analyzed $(n=5)$. Asterisks indicate a significant difference to WT rice based on a $t$ test. *: significant difference compared to WT rice at a $5 \%$ level $(P<0.05)$; **: significant difference compared to WT rice at a $1 \%$ level $(P<0.01)$

both shorter than that of the wild type, and leaf width was narrower than the wild type (Fig. 4c-f). The average plant height of U-16 was less than $50 \mathrm{~cm}$ but the average tiller number was more than 40 , accompanied by narrower and shorter leaves compared to the wild type (Fig. 4c). Most transformants of D18-11 plants were able to grow up to over $90 \mathrm{~cm}$ in height. No severe dwarf lines similar to the U-16 transformants were observed. The tiller number of D18-11 and the wild type did not increase from 60 to 120 days after transplanting (DAT), while U-16 went on to initiate and formed many nonproductive tillers in the same period (Fig. 4c-f).

After the heading stage, the axillary buds both in U-16 and D18-11 displayed a remarkable difference from the wild type. All axillary tiller buds remained dormant and rarely outgrew in the wild type, whereas nearly all axillary buds outgrew and eventually formed tillers in U-16. Some axillary buds in D18-11 outgrew and formed young tillers around the unelongated basal nodes, but the axillary buds on the elongated nodes remained dormant as in the wild type (Fig. 5a).

As a complex trait in rice, grain yield is multiplicatively determined by three components: the number of panicles, number of grains per panicle and grain weight [49]. Compared to the wild type, more tillers with shorter panicles and fewer filled grains were produced in U-16 in the pot experiment (Table 1). The yield related traits were also noticeably impaired, thus the actual grain yield was significantly reduced in U-16 (Table 1). In contrast, D18-11 showed no deleterious effects on reproductive organs, and no significant difference was observed in main panicle length and filled grain percentage between the D18-11 and 


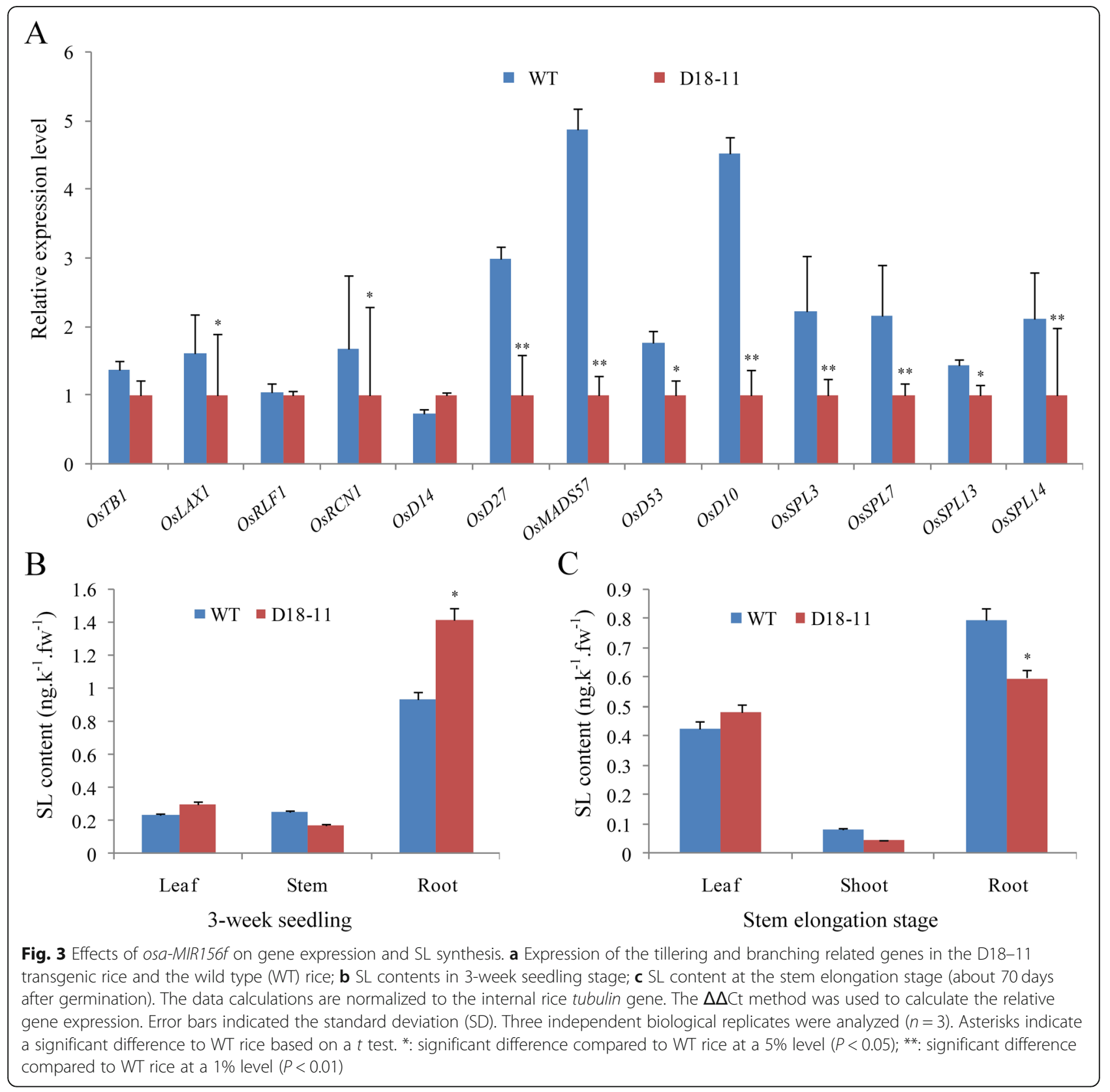

Table 1 Yield traits of different rice lines in the seasonal crop

\begin{tabular}{llll}
\hline Yield traits & WT & D18-11 & U-16 \\
\hline Tiller number per plant & $7.4 \pm 0.9$ & $9.1 \pm 2.4^{*}$ & $46.8 \pm 15.6^{* *}$ \\
Main panicle length (cm) & $22.49 \pm 1.61$ & $21.70 \pm 0.76 \mathrm{NS}$ & $7.94 \pm 1.04^{* *}$ \\
Total grains per main panicle & $126.0 \pm 17.1$ & $127.0 \pm 10.9 \mathrm{NS}$ & $10.7 \pm 2.2^{* *}$ \\
Filled grains per main panicle & $97.1 \pm 12.4$ & $85.6 \pm 13.3^{*}$ & $7.5 \pm 2.0^{* *}$ \\
Filled grain percentage (\%) & $82.3 \pm 5.0$ & $75.2 \pm 14.8^{*}$ & $70.9 \pm 13.9^{* *}$ \\
1000-grain weight (g) & $24.3 \pm 0.7$ & $22.7 \pm 0.5 \mathrm{NS}$ & $18.2 \pm 0.1^{* *}$ \\
Grain yield per plant (g) & $14.6 \pm 1.3$ & $18.1 \pm 3.6^{* *}$ & $2.9 \pm 0.6^{* *}$ \\
\hline
\end{tabular}

Values are the means \pm SD of three biological replicates $(n=150)$. Asterisks indicate a significant difference compared to the wild type (WT) rice based on a $t$ test. **: significant difference compared to WT rice at $1 \%$ level $(P<0.01)$; ${ }^{*}$ : significant difference compared to WT rice at $5 \%$ level $(P<0.05)$; NS: no significant difference 

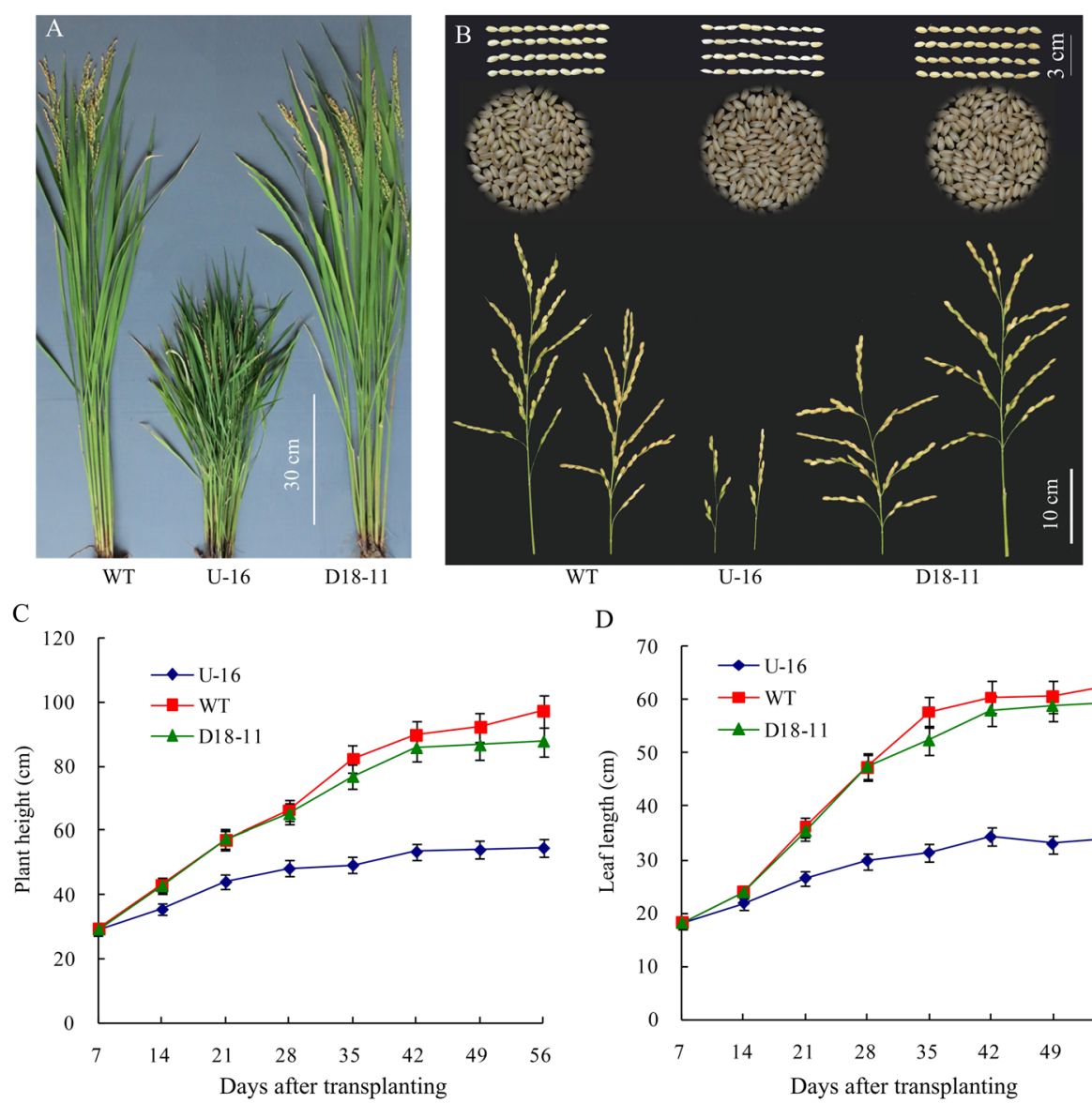

$\mathrm{D}$
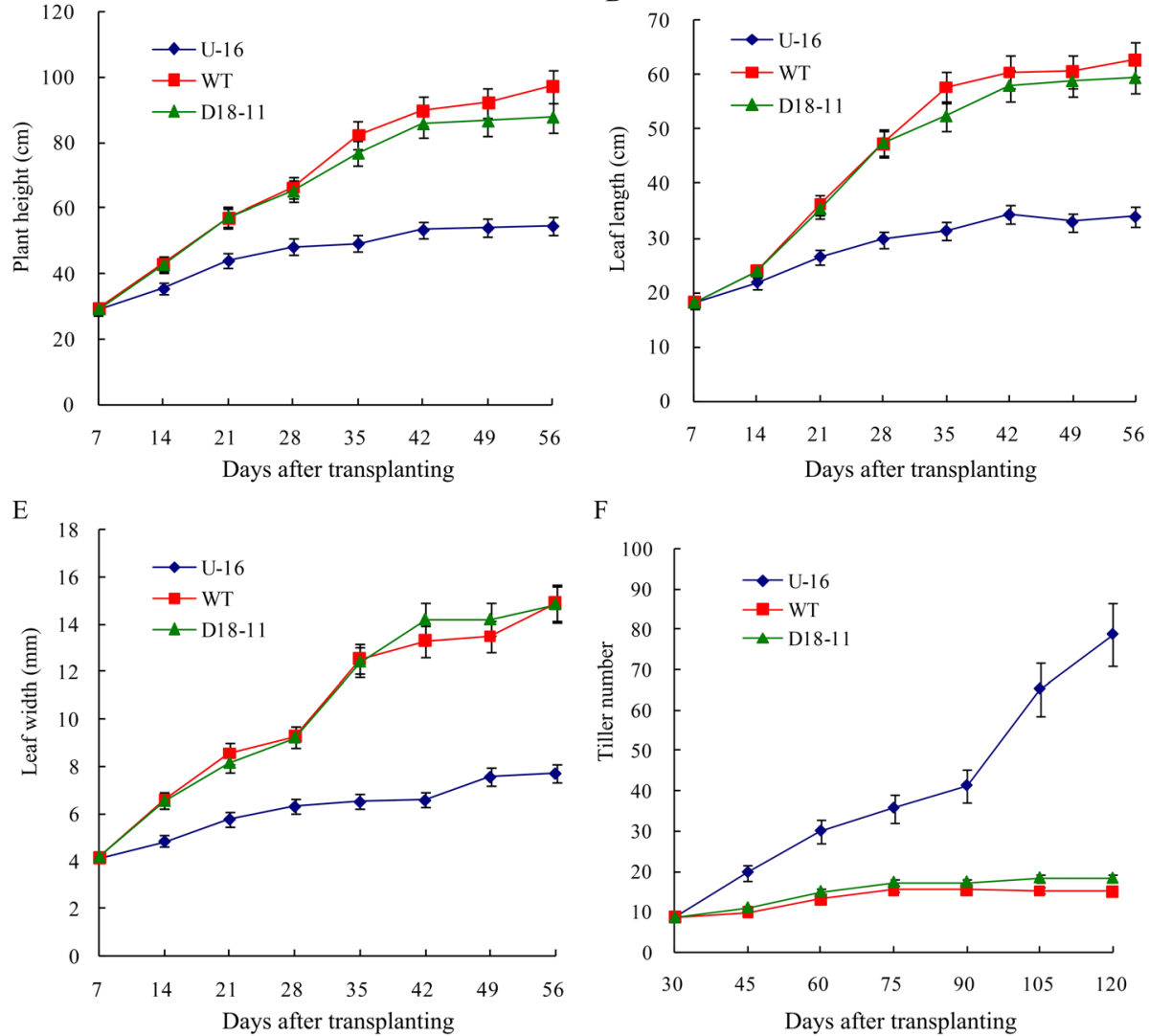

Fig. 4 Effects of osa-MIR156f on plant architecture in the seasonal rice. a Phenotype of 110 days old seasonal rice the in the wild type, U-16, and D18-11; $\mathbf{b}$ Effects of osa-MIR156f on the panicle and grains in the wild type, U-16 and D18-11; For the wild type, U-16 and D18-11, the grain lengths $(\mathrm{cm})$ were $0.721 \pm 0.035,0.712 \pm 0.027$ and $0.715 \pm 0.058$ respectively, and the grain width $(\mathrm{cm})$ were $0.311 \pm 0.046,0.285 \pm 0.046$ and $0.315 \pm 0.024$ respectively; $\mathbf{c}-\mathbf{f}$ Effects of osa-MIR156f on the plant height, leaf width, leaf length and tiller number in seasonal rice. Three independent biological replicates were analyzed $(n=50)$. Error bars indicated the standard deviation (SD)

the wild type. Due to more effective tillers, D18-11 had an increased grain yield of up to $18.1 \mathrm{~g}$ per plant compared to $14.6 \mathrm{~g}$ per plant in the wild type, suggesting the possibility for improving plant architecture and yield potential. The grain yield per plant in D18-11 was further evaluated by field trial. D18-11 showed no difference to the wild type in main panicles length, but effective tiller number and grain yield per plant were distinctly increased (Table 1 ). These results indicated that the stem-specific expression of osaMIR156f driven by the D18 promoter may create an improved plant architecture with more effective tillers and no panicle defects, although the constitutive overexpression of 


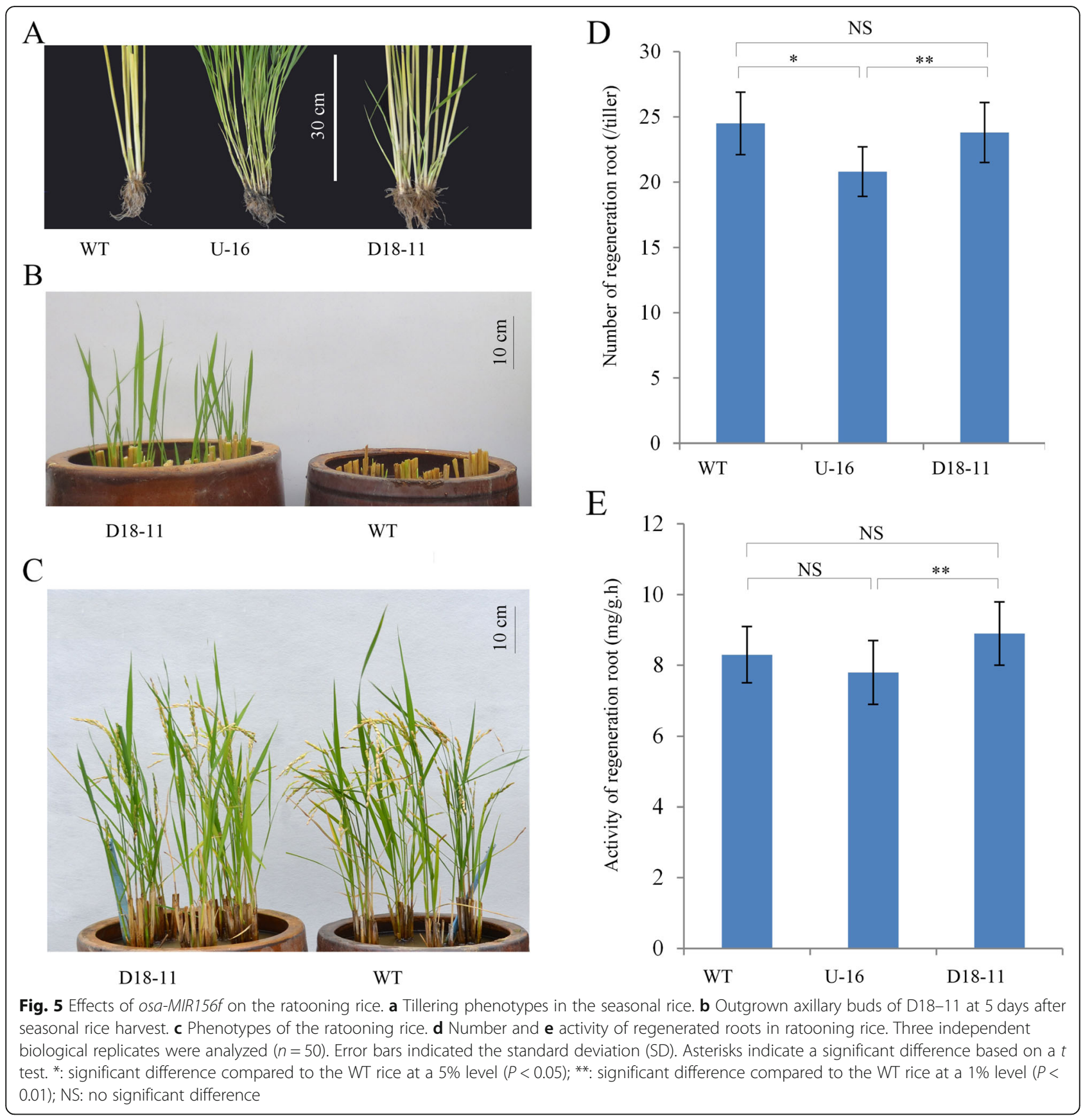

osa-MIR156 $f$ resulted in seriously impaired reproductive development.

\section{D18pro::osa-MIR156f Transgenic Plants Showed Superior Ratooning Performance}

In the cultivation practice of ratooning rice, the outgrown buds from the last two nodes are easy to form effective tillers, but the buds from the basal node are considered inferior because of their longer growth time. Fortunately, the axillary buds of D18-11 around the basal nodes would outgrow in advance before the harvest of seasonal rice (Fig. 5a). This ensured that early outgrown buds could develop into effective tillers and contribute to the grain yield of ratooning rice within 50 to 60 days (Fig. $5 \mathrm{~b}-\mathrm{c}$ ). Therefore, the outgrown buds in advance were useful for tapping the potential of ratooning rice yield (Table 2). To evaluate whether those earlier sprouting axillary tiller buds contributed to the ratooning rice yield, we investigated ratooning performance related agronomic traits of D18-11 and the wild type after the harvest of seasonal rice. D18-11 showed moderate plant height, more effective tillers, and higher grain yield per plant compared to the wild type (Table 2). 
Table 2 Agronomic traits of D18-11 and wild type in seasonal and ratooning crop

\begin{tabular}{|c|c|c|c|c|}
\hline \multirow[t]{2}{*}{ Traits } & \multicolumn{2}{|l|}{ WT } & \multicolumn{2}{|l|}{ D18-11 } \\
\hline & Seasonal & Ratooning & Seasonal & Ratooning \\
\hline Plant height (cm) & $87.6 \pm 4.4$ & $53.37 \pm 1.9$ & $84.5 \pm 6.2^{*}$ & $50.62 \pm 4.8 \mathrm{NS}$ \\
\hline Tiller number per plant & $6.6 \pm 1.7$ & $7 \pm 1.4$ & $9.1 \pm 1.2^{* *}$ & $8.7 \pm 2.6^{*}$ \\
\hline Main panicle length $(\mathrm{cm})$ & $20.68 \pm 1.84$ & $11.38 \pm 2.58$ & $20.04 \pm 1.73$ NS & $11.33 \pm 2.40 \mathrm{NS}$ \\
\hline 1000-grain weight (g) & $24.38 \pm 0.21$ & $24.22 \pm 0.19$ & $22.80 \pm 0.55 \mathrm{NS}$ & $23.89 \pm 0.31 \mathrm{~N} S$ \\
\hline Grain yield per plant (g) & $12.26 \pm 2.49$ & $2.54 \pm 0.40$ & $16.82 \pm 2.93^{* *}$ & $2.68 \pm 0.23^{*}$ \\
\hline Root activity (mg/g.h) & / & $8.3 \pm 0.8$ & / & $8.9 \pm 0.9$ \\
\hline
\end{tabular}

Values are the means \pm SD of three biological replicates $(n=50)$. Asterisks indicate a significant difference compared to wild type (WT) rice based on a $t$ test. *: significant difference compared to WT rice at $5 \%$ level $(P<0.05)$; ${ }^{* *}$ : significant difference compared to WT rice at $1 \%$ level $(P<0.01)$; NS: no significant difference. /: represented no dada collected

In addition, both the number and activity of newly regenerated roots per tiller showed no significant difference between D18-11 and the wild type in ratooning rice, but the root activity of U-16 was significantly decreased compared to D18-11 and the wild type (Fig. $5 \mathrm{~d}$ and e, Table 2). The results indicated that manipulating the expression of osaMIR156f in stem using the D18 promoter did not affect both the quantity and activity of ratooning rice roots.

\section{Discussion}

osa-MIR156f Systematically Regulates Expression of Tillering Related Genes in Shoot

Rice tillering and branching are largely controlled through the miR156/SPL pathway. Previous studies indicated that miR156 promotes tiller branching, but negatively regulates the activity of the inflorescence meristem $[26,38]$. Recently, more regulators have been identified and more interactions among D53, SPL3/17, TB1, and LAX1/RFL have been elucidated in this pathway [11, 20-23, 40]. Many rice panicle development related genes, including MADS34, SPLs, LAX1 and RFL, are down-regulated in osa-MIR156 overexpression plant [23]. The expression regulation of tillering/branching related regulators was briefly summarized in Fig. 6a. osamiR156 targets SPLs and reduces their transcriptional level. The transcription of TB1 is activated by SPL3/17, but represses by D53 [19]. MADS57 and TB1 can be assembled to a heterodimer and then suppress the expression of $D 14$ [20]. LAX1 and RFL are highly co-expressed with SPLs [22]. The expression of RCN1 is suppressed by MADS34, but further evidence is still needed [24, 25].

In this study, a transgenic rice line was generated by harboring osa-MIR156f pro::GUS to observe the expression pattern of osa-MIR156f. High GUS expression was found in the young tissues. Osa-MIR156f was mainly expressed in the root tip, elongating zone and root hair (Fig. 1b). The expression of tillering related genes in the transgenic line was detected and their relationship was analyzed. The stem specific expression of osa-MIR156f driven by the $D 18$ promoter extremely down-regulated the transcriptional levels of MADS57, D10, D27 and SPLs in the stem (Fig. 3a). A previous research found that MADS57 expression was higher at the tillering and stem-elongation stages than at other stages in rice [20]. A high transcriptional level of MADS57 was found in the sheaths and leaves, but weak signals were observed in the culm [20]. osa-MIR156f in stem may further decrease the level of MADS57 mRNA and then promote the expression of D14 (Fig. 3a). Slightly higher level of D14 may cause moderate height and more effective tillers, but not severe dwarfism and excessive ineffective tillers in D18-11 (Fig. 2a). osa-MIR156f in rice stem has little effect on the transcriptional levels of TB1, $L A X 1$ and RFL1 because these three genes are mainly expressed in the panicles. Unexpectedly, it was found that RCN1 was down-regulated in the stem, but another study indicated that $R C N 1$ was up-regulated in panicles of miR156 overexpression plants [23]. Furthermore, it was found that MIR156f significantly inhibited the expression of D10 and D27, which encode two important enzymes in SL biosynthesis. Moreover, the SL contents were significantly decreased both in the shoot and stem of D18-11. osa-miR156 may regulate SL biosynthesis in addition to signaling through an unknown pathway (Fig. 6a). Overall, the plant architecture of D18-11 is the result of the systematical regulation by multiple regulators, including SPLs, MADSs and SL signaling genes.

\section{Manipulation of osa-MIR156f Shaped Plant Architecture and Yield Traits both in Seasonal and Ratooning Rice}

For an individual plant, the rice grain yield is determined by the number of effective tillers (panicles), number of grains per panicle, and grain weight [49]. In addition, plant architecture is also a very important determinant of yield per unit area. To obtain high rice gain yield, breeding efforts in the past 50 years have brought about two great advancements in yield through the application of the semi-dwarf gene and development of hybrid rice. Super-rice breeding programs have achieved great success. Identification of IPA alleles has been a critical 

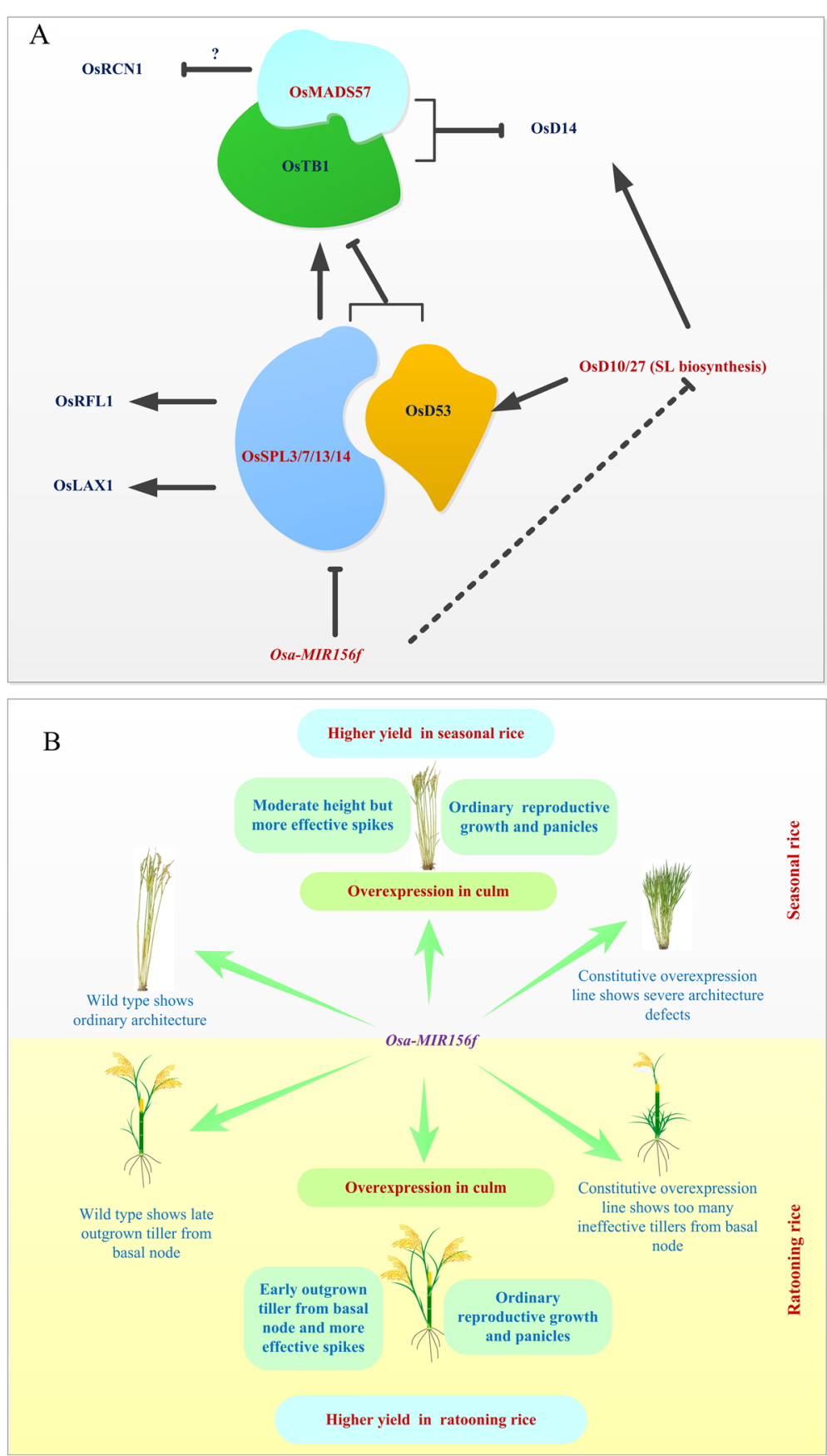

Fig. 6 Effects of osa-MIR156f on (a) expression of tillering and branching regulators and (b) plant architecture in rice

objective for enhancing global food security. Among them, IPA1 dampens tiller branching, but increases panicle branching and grain weight together with strengthening culms $[13,14]$. IPA traits can be fine-tuned by manipulating IPA1 expression, thus an optimal IPA1 expression may lead to an ideal plant architecture and yield, which demonstrates a practical approach to the efficient design of elite super rice varieties [50]. It has been demonstrated that the miR156/SPL pathway manipulates a large range of processes underlying plant growth and development, including embryonic patterning, phase change and plant architecture establishment [51]. As the controller of SPLs, the activities of miR156 are so influential that the constitutive overexpression of osaMIR156 led to severe defects in tillering and branching [26, 38] (Figs. 1 and 6b). More tillers with shorter panicles and fewer grains were produced in the U-16 plants. The U-16 plants showed a drastic reduction in panicle 
branches and filled grain number per panicle. The yield traits (as mentioned above) were also noticeably impaired in the U-16 line (Table 1, Fig. 6b). Fortunately, the osa-MIR156 $f$ in rice shoot was specifically expressed by $D 18$ promoter and a semi-dwarf transformant with more effective panicles and high grain yield was identified (Fig. 2a, Table 2).

Ratooning can achieve 'one crop with two harvests' in rice cultivation and is an important measure to increase rice grain yield and to reduce production costs, especially under the current situation of rising costs of labor force. After the harvest of seasonal rice, fast and simultaneous outgrowth of axillary buds is crucial because late ratooning will usually encounter the low temperature stress. In this study, an important finding is the improvement of ratooning performance by manipulating the expression of osa-MIR156f. It was found that the axillary buds in basal node would outgrow in advance before the harvest of seasonal rice in D18-11, while the axillary buds of the wild type would largely remain dormant at the same time (Fig. $6 b)$. New tillers would quickly outgrow from the basal and the last one to two nodes in D18-11, thus the ratooning rice grain yield was significantly higher than that of the wild type. Therefore, specific expression of osa-MIR156f in the shoot could be applicable in future genetic breeding for shaping plant architecture and yield traits both in seasonal and ratooning rice.

\section{Conclusion}

In this study, osa-MIR156 $f$ was specifically expressed in the rice stem under the control of the promoter D18. The transgenic line showed moderate height and more effective tillers. Moreover, the grain yield was significantly increased both in seasonal and ratooning rice. The controlling expression of osa-MIR156f may have the great potential of application in rice genetic breeding. In addition, we found that osa-miR156f down-regulated the expression of tillering regulators, such as TB1 and $L A X 1$. The expression of D10,D27 and D53, being involved in the biosynthesis and signaling of strigolactone (SL), decreased in the stem of the D18-11 transgenic line.

\section{Methods}

\section{Plant Materials}

The cultivated rice O. sativa spp. japonica cv. Nipponbare was used for osa-MIR156f transformation. Rice plants of the transgenic lines and the wild type were grown in pots in a net-house under natural conditions, and necessary management practices were provided as required for proper growth. At the full heading stage, all stems of each hills were removed by hand to leave an approximately $10 \mathrm{~cm}$ of stubble, and sample pots were randomly selected to assess the ratooning performance.

\section{Plasmid Construction and Plant Transformation}

The osa-MIR156f (Additional file 1: Supplemental file S1) was amplified through PCR from the Nipponbare genomic DNA by using the primers 5 -CGCCCACCTTTCTTCTCC CA-3' and 5'-AAGGAGCAGTTAGATAATGGAG-3'. To generate UBQpro::osa-MIR156f in which the osa-MIR156f gene is driven by a Ubiquitin1 promoter, a fragment of osaMIR156 $f$ was cloned into the EcoR V site of pBluescriptSK+ (pBS) (designated as pBS-MIR156f) and subsequently sequenced. The maize Ubiquitin1 promoter was collected from the plasmid pBS-pUbq by digesting with Hind III/ BamH I. The pBS-MIR156f was digested by Sal I/BamH I to obtain the fragment including osa-MIR156f. The pWM101 vector was digested by Hind III/Sal I, and then ligated with Ubiquitin1 promoter and osa-MIR156f to obtain UBQpro::osa-MIR156f. To generate D18pro::osa-MIR156f in which the osa-MIR156f gene is driven by the $D 18$ promoter (Additional file 1: Supplemental file S2), the maize Ubiquitin1 promoter of UBQpro::osa-MIR156f was removed and replaced by a $2.1-\mathrm{kb}$ segment of the $D 18$ promoter [46].

To generate the osa-MIR156f pro::GUS construct, $3 \mathrm{~kb}$ of the promoter region was predicted by using PlantCARE method (http://bioinformatics.psb.ugent.be/webtools/ plantcare/html/) and was cloned from Nipponbare genomic DNA. The promoter of osa-MIR156f (a $3 \mathrm{~kb}$ fragment in upstream region of pre-miRNA156f) was amplified by using the primers $5^{\prime}$-ATGGAATAAATGGCGCCGTGTAC-3' and 5'-ACTGCCACCACCCAAAACCAAGA-3', and then cloned into the $p K G W S 7-$ Gateway-GUS plasmid to generate the osa-MIR156f pro::GUS vector by an LR reaction. An Agrobacterium tumefaciens mediated transformation method as previously reported by Hiei and Komari [52] .

\section{Realtime-qPCR and Stem-Loop RT PCR}

The leaves, basal nodes and roots respectively at the 3week-old seedling stage and the tillering stage, the stem at elongation stage and the young spikes at the heading stage were used for gene expression analysis. Tissues from 5 individual plants were pooled. Total RNA was isolated from $100 \mathrm{mg}$ of tissues using a Trizol reagent (Invitrogen) and treated with RNase-free DNase I (Invitrogen) according to the manufacturer's instructions. Approximately $5 \mu \mathrm{g}$ of high-quality RNA was used to synthesize first-strand cDNA using poly (dT) oligo primer according to the manufacturer's instructions in $\mathrm{M}$ MLV kit (Invitrogen). Eppendorf BioPhotometer Plus (Germany) was used to analyze RNA/cDNA quality and to quantify RNA/cDNA concentration. PCR was carried out in a reaction system with a total volume of $20 \mu \mathrm{L}$, which contained $0.2 \mu \mathrm{L}$ cDNA, $0.2 \mu \mathrm{M}$ each specific primer and SYBR Green I (Invitrogen) on a CFX96 system (BIO-RAD). The following programs were employed: pre-denaturing for $30 \mathrm{~s}$ at $95^{\circ} \mathrm{C}$, then amplification for 40 cycles including denaturation for $10 \mathrm{~s}$ at $95^{\circ} \mathrm{C}$, and 
annealing for $30 \mathrm{~s}$ at $60{ }^{\circ} \mathrm{C}$. Both the tillering related genes and pri-miR156f were normalized to the internal rice tubulin $\beta-4$ gene.

Stem-loop reverse transcription quantitative PCR (stemloop RT PCR) [53] was employed to detect the mature osa-miR156f, and U6 snRNA was used as an internal control. Reverse transcription in a $20 \mu \mathrm{L}$ reaction system (containing $1 \mu \mathrm{g}$ RNA, $1 \mu \mathrm{M}$ each primer, $0.5 \mu \mathrm{L}$ Invitrogen M-MLV reverse transcriptase) was conducted in an thermal cycler using a pulsed RT program as follows: incubate for $30 \mathrm{~min}$ at $16^{\circ} \mathrm{C}, 60$ cycles at $30^{\circ} \mathrm{C}$ for $30 \mathrm{~s}, 42^{\circ} \mathrm{C}$ for $30 \mathrm{~s}$ and $50^{\circ} \mathrm{C}$ for $1 \mathrm{~s}$, followed by incubation at $85^{\circ} \mathrm{C}$ for 5 min to inactivate the reverse transcriptase. cDNA concentration was quantified by using Eppendorf BioPhotometer Plus (Germany) and same amount of cDNA was used as the template for the next Stem-loop PCR. Stem-loop PCR was carried out in a reaction system with a total volume of $20 \mu \mathrm{L}$, which contained SYBR Green I (Invitrogen) on a CFX96 system (BIO-RAD). The following programs were employed: pre-denaturing for $30 \mathrm{~s}$ at $95^{\circ} \mathrm{C}$, then amplification for 40 cycles including denaturation for $10 \mathrm{~s}$ at $95^{\circ} \mathrm{C}$, and annealing for $30 \mathrm{~s}$ at $60^{\circ} \mathrm{C}$.

For melting curve analysis, reaction mix was denatured samples at $95^{\circ} \mathrm{C}$, then cooled to $60^{\circ} \mathrm{C}$. The amplification specificity was monitored by collecting fluorescence signals continuously from $60^{\circ} \mathrm{C}$ to $95^{\circ} \mathrm{C}$ at $0.5^{\circ} \mathrm{C}$ per second. The $\Delta \Delta \mathrm{Ct}$ method was used to calculate the gene relative expression. The primers used were listed in the Additional file 1: Supplemental file S3. Three independent biological replicates were analyzed $(n=3)$.

\section{GUS Staining}

Five osa-MIR156fpro::GUS transgenic plants were used for GUS staining analysis. The tissues for analysis including leaves and roots respectively collected at the seedling, the tillering and the heading stage. The sampling dates for additional tissues were as follows: shoot apexes at the 3-week-old seedling stage, axillary buds at the tillering and heading stage, basal nodes at the tillering and heading stage, stem segments at the stem elongation and flowering stage, spikes at the heading stage, and stamen at the flowering stage. These tissues were washed three times with $100 \mathrm{mM}$ phosphate buffer $(\mathrm{pH}$ 7.0), and then incubated in a staining solution $[100 \mathrm{mM}$ phosphate buffer (pH 7.0), $10 \mathrm{mM}$ EDTA, $2 \mathrm{mM}$ 5bromo-4-chloro-3-indolyl-b-GlcA, $5 \mathrm{mM} \mathrm{K}_{4} \mathrm{Fe}(\mathrm{CN})_{6}, 5$ $\mathrm{mM} \mathrm{K}_{3} \mathrm{Fe}(\mathrm{CN})_{6}$, and $0.2 \%$ Triton X-100] for $24 \mathrm{~h}$ at $37^{\circ} \mathrm{C}$. The stained tissues were finally observed after soaked in $90 \%$ alcohol for $24-48 \mathrm{~h}$ [54].

\section{Strigolactone Extraction and Determination}

Rice tissue was ground in liquid nitrogen and about 200 mg well ground sample was loaded to a $2.0 \mathrm{~mL}$ vial. After the addition of $1.0 \mathrm{~mL}$ of acetone (HPLC grade,
Tedia), the homogenates were mixed by stirring in an ultrasonic bath and stored overnight at $-20^{\circ} \mathrm{C}$. After being centrifuged at $15,200 \mathrm{~g}$ for $10 \mathrm{~min}$, the supernatant was collected and then vacuumed to dryness by RCT-60 concentrator (Jouan). Dried extract was dissolved in $300 \mu \mathrm{L}$ of methanol (HPLC grade, Merck) solution and then passed through a Sep-Pak $\mathrm{C}_{18}$ cartridge (Waters, USA). The cartridge was eluted with $1500 \mu \mathrm{L}$ of $80 \%$ methanol, and the eluate was once again vacuum-dried. After re-dissolving in $50 \mu \mathrm{L}$ of $80 \%$ methanol, $10 \mu \mathrm{L}$ of sample solution was injected into the liquid chromatography-tandem mass spectrometry system (LC-MS/MS 8030 plus, Shimadzu, Japan).

Liquid chromatography was performed using a 2.0 i.d. $\mathrm{mm} \times 75 \mathrm{~mm}$ Shim-pack XR-ODSI column $(2.2 \mu \mathrm{m}$, Shimadzu) at a column temperature of $40^{\circ} \mathrm{C}$. The mobile phase comprising solvent $\mathrm{A}(0.1 \% \mathrm{v} / \mathrm{v}$ aqueous formic acid) and solvent B ( $100 \% \mathrm{v} / \mathrm{v}$ acetonitrile) was employed in a gradient mode simply described as "min/\%/\%," i.e., retention time/concentration of $\mathrm{A} /$ concentration of $\mathrm{B}$. The gradient program for SL was 0/90/10, 12/0/100, 13/0/100, 14/90/10. The flow rate of the mobile phase was $0.25 \mathrm{~mL} \cdot \mathrm{min}^{-1}$.

The mass system was set to multiple-reaction-monitoring mode using electrospray ionization in the positive ion mode. 5-dexoxystrigol (5-DS, Strigolab) was used as an external standard for SL analysis. Optimized mass operation conditions were employed as follows: nebulizing gas flow $\left(1.5 \mathrm{~L} \cdot \mathrm{min}^{-1}\right)$, drying gas flow $\left(12 \mathrm{~L} \cdot \mathrm{min}^{-1}\right)$, desolvation temperature $\left(200^{\circ} \mathrm{C}\right)$ and heat block temperature $\left(500^{\circ} \mathrm{C}\right)$. For 5-DS quantitive analysis, quadrupole 1 pre-bias of -17 $\mathrm{eV}$, quadrupole 3 pre-bias of $-22 \mathrm{eV}$, collision energy of $17 \mathrm{eV}$, mass-to-charge ratio $(\mathrm{m} / \mathrm{z})$ of $331.1 / 216.2$ were employed. The SL concentration was eventually calculated according to the calibration curve established by using 5DS solution at different concentrations, and a good linear determination coefficients $R^{2}(0.9967)$ of the calibration curve was obtained for all the analytes. Three independent biological replicates were analyzed.

\section{Morphological Observations and Yield Related Traits Investigation}

Plant height, leaf length and leaf width were measured weekly from the day after transplanting, and tiller number was investigated at a 15-day interval from 30 days after transplanting. The yield related traits, including tiller number per plant, main panicle length $(\mathrm{cm})$, spikelet number per panicle, filled grain number per panicle, 1000-grain weight (g), and grain yield per plant (g) were recorded after harvest. For the ratooning performance, plant height, number of tillers and total grain weight per hill were measured. Three independent biological replicates were analyzed.

\section{Root Number and Root Activity Analysis}

After the seasonal rice harvest, old roots were cut off from the rice stubble and the rice stubble was replanted 
in soil. After culturing for 7 days, the number of the regenerated roots was counted. A TTC (2,3,5-triphenytetrazolium chloride) method [55] was employed to analyze the root activity of regenerated roots. TTC (Sigma) was dissolved in $100 \mathrm{mM}$ sodium phosphate buffer ( $\mathrm{pH} 7.0)$ to a final concentration of $0.6 \%(\mathrm{w} / \mathrm{v})$. Root segments about $1 \mathrm{~cm}$ to $3 \mathrm{~cm}$ in length, were collected and washed with sterile water for $10 \mathrm{~min}$. The root segments were transferred into $1 \mathrm{~mL}$ of TTC solution and incubated for $1 \mathrm{~h}$ at $37^{\circ} \mathrm{C}$ in the dark. The TTC solution was removed and the root segments were rinsed once with deionized water. For the extraction process, the root segments were incubated overnight at room temperature in $2 \mathrm{~mL}$ of $95 \%(\mathrm{v} / \mathrm{v})$ ethanol. The reduction of TTC was expressed as the absorbance of the extracted solutions at $520 \mathrm{~nm}$ in a spectrophotometer. Three independent biological replicates were analyzed.

\section{Supplementary information}

Supplementary information accompanies this paper at https://doi.org/10. 1186/s12575-019-0110-4.

Additional file 1. Supplemental file S1-S6.

\section{Acknowledgements}

We thank Professor Lizhong Xiong (Huazhong Agricultural University) for kindly providing the overexpressed osa-MIR156d line seeds. We thank Professor Li-Jia Qu, Professor Genji Qin, Dr. Tong Wei, Dr. Qing Tao, and Dr. Dongshu Guo (Peking University) for their valuable suggestions or technical assistance.

\section{Authors' Contributions}

QL, YS and LX designed the research; QL, YS, YZ and MG performed the research; $\mathrm{KP}, \mathrm{BH}, \mathrm{RW}$ and $\mathrm{LX}$ analyzed the data; $\mathrm{QL}, \mathrm{YS}$ and $\mathrm{LX}$ wrote the paper. All authors discussed the results and commented on the manuscript. $\mathrm{QL}$ and $\mathrm{YS}$ are the equal contribution authors. All authors read and approved the final manuscript.

\section{Funding}

This work was jointly supported by National Natural Science Foundation of China (91317312, 31570372 and 91417300-03), Hunan Provincial Natural Science Foundation of China (2016JJ2065), Scientific Research Fund of Hunan Provincial Education Department (grant number 18 K042), Planning Projects of Changsha Science and Technology Bureau (k0803269-21) and Hunan Provincial Key Laboratory for Crop Germplasm Innovation and Utilization (18KFXM06)

\section{Availability of Data and Materials}

The datasets measured and analyzed during the study are available from the corresponding authors upon reasonable request.

\section{Ethics Approval and Consent to Participate}

This article does not contain any studies with human participants.

\section{Consent for Publication}

Not applicable.

\section{Competing Interests}

The authors declare that they have no competing interests.

\section{Author details}

${ }^{1}$ Hunan Provincial Key Laboratory of Phytohormones and Growth Development, Hunan Agricultural University, Changsha 410128, China.

${ }^{2}$ Southern Regional Collaborative Innovation Center for Grain and Oil Crops in China, Hunan Agricultural University, Changsha 410128, China. ${ }^{3}$ Hengyang Medical College, University of South China, Hengyang 421001, China. ${ }^{4}$ Rice Research and Training Center, Field Crops Research Institute, Agriculture Research Center, Giza 33717, Egypt.

Received: 13 August 2019 Accepted: 21 October 2019

Published online: 04 November 2019

\section{References}

1. Pennisi E. Plant genetics. The blue revolution, drop by drop, gene by gene. Science. 2008;320(5873):171-3.

2. Tilman D, Balzer C, Hill J, Befort B. Global food demand and the sustainable intensification of agriculture. Proc Natl Acad Sci. 2011;108(50):20260-4.

3. Khush G. Green revolution: the way forward. Nat Rev Genet. 2001;2(10):815-22.

4. Wang Y, Li J. Branching in rice. Curr Opin Plant Biol. 2011;14(1):94-9.

5. Ashikari M, Sakakibara H, Lin S, Yamamoto T, Takashi T, Nishimura A, Angeles ER, Qian Q, Kitano H, Matsuoka M. Cytokinin oxidase regulates rice grain production. Science. 2005;309:741-5.

6. Ikeda-Kawakatsu K, Yasuno N, Oikawa T, lida S, Nagato Y, Maekawa M, Kyozuka J. Expression level of ABERRANT PANICLE ORGANIZATION1 determines rice inflorescence form through control of cell proliferation in the meristem. Plant Physiol. 2009;150(2):736-47.

7. Fan C, Xing Y, Mao H, Lu T, Han B, Xu C, Li X, Zhang Q. GS3, a major QTL for grain length and weight and minor QTL for grain width and thickness in rice, encodes a putative transmembrane protein. Theor Appl Genet. 2006; 112:1164-71.

8. Song XJ, Huang W, Shi M, Zhu MZ, Lin H. A QTL for rice grain width and weight encodes a previously unknown RING-type E3 ubiquitinligase. Nat Genet. 2007:39:623-30

9. Shomura A, Izawa T, Ebana K, Ebitani T, Kanegae H, Konishi S, Yano M. Deletion in a gene associated with grain size increased yields during rice domestication. Nat Genet. 2008;40:1023-8.

10. Si L, Chen J, Huang X, Gong H, Luo J, Hou Q, Zhou T, Lu T, Zhu J, Shangguan $Y$, et al. OsSPL13 controls grain size in cultivated rice. Nat Genet. 2016:48(4):447-56.

11. Komatsu K, Maekawa M, Ujiie S, Satake Y, Furutani I, Okamoto H, Shimamoto K, Kyozuka J. LAX and SPA: major regulators of shoot branching in rice. Proc Nat Acad Sci. 2003;100(20):11765-70.

12. Oikawa T, Kyozuka J. Two-step regulation of LAX PANICLE1 protein accumulation in axillary meristem formation in rice. Plant Cell. 2009;21(4):1095-108.

13. Jiao Y, Wang Y, Xue D, Wang J, Yan M, Liu G, Dong G, Zeng D, Lu Z, Zhu X, et al. Regulation of OsSPL14 by OsmiR156 defines ideal plant architecture in rice. Nat Genet. 2010;42(6):541-4.

14. Miura K, Ikeda M, Matsubara A, Song X, Ito M, Asano K, Matsuoka M, Kitano $\mathrm{H}$, Ashikari M. OsSPL14 promotes panicle branching and higher grain productivity in rice. Nat Genet. 2010;42(6):545-9.

15. Takeda T, Suwa Y, Suzuki M, Kitano H, Ueguchi-Tanaka M, Ashikari M, Matsuoka M, Ueguchi C. The OsTB1 gene negatively regulates lateral branching in rice. Plant J. 2003;33:513-20.

16. Li X, Qian Q, Fu Z, Wang Y, Xiong G, Zeng D, Wang X, Liu X, Teng S, Hiroshi $F$, et al. Control of tillering in rice. Nature. 2003;422(6932):618-21.

17. Ikeda M, Miura K, Aya K, Kitano H, Matsuoka M. Genes offering the potential for designing yield-related traits in rice. Curr Opin Plant Biol. 2013;16(2):21320.

18. Lu Z, Yu H, Xiong G, Wang J, Jiao Y, Liu G, Jing Y, Meng X, Hu X, Qian Q. Genome-wide binding analysis of the transcription activator IDEAL PLANT ARCHITECTURE1 reveals a complex network regulating rice plant ARCHITECTURE. Plant Cell. 2013;25(10):3743-59.

19. Liu J, Cheng X, Liu P, Suna J. miR156-targeted SBP-box transcription factors interact with DWARF53 to regulate TEOSINTE BRANCHED1 and BARREN STALK1 expression in bread wheat. Plant Physiol. 2017;174(3):1931-48.

20. Guo S, Xu Y, Liu H, Mao Z, Zhang C, Ma Y, Zhang Q, Meng Z, Chong K. The interaction between OsMADS57 and OsTB1 modulates rice tillering via DWARF14. Nat Commun. 2013;4:1566

21. Ikeda-Kawakatsu K, Maekawa M, Izawa T, Itoh Jl, Nagato Y. ABERRANT PANICLE ORGANIZATION 2/RFL, the rice ortholog of Arabidopsis LEAFY, suppresses the transition from inflorescence meristem to floral meristem through interaction with APO1. Plant J. 2012;69(1):168-80.

22. Wang $L$, Xie W, Chen Y, Tang W, Yang J, Ye R, Liu L, Lin Y, Xu C, Xiao J, et al. A dynamic gene expression atlas covering the entire life cycle of rice. Plant J. 2010;61(5):752-66 
23. Wang L, Sun S, Jin J, Fu D, Yang X, Weng X, Xu C, Li X, Xiao J, Zhang Q. Coordinated regulation of vegetative and reproductive branching in rice. Proc Nat Acad Sci. 2015;112(50):15504-9.

24. Gao X, Liang W, Yin C, Ji S, Wang H, Su X, Guo C, Kong H, Xue H, Zhang D. The SEPALLATA-like gene OSMADS34 is required for rice inflorescence and spikelet development. Plant Physiol. 2010;153(2):728-40.

25. Liu C, Teo Z, Bi Y, Song S, Xi W, Yang X, Yin Z, Yu H. A conserved genetic pathway determines inflorescence architecture in Arabidopsis and rice. Dev Cell. 2013;24(6):612-22

26. Xie K, Wu C, Xiong L. Genomic organization, differential expression, and interaction of SQUAMOSA promoter-binding-like transcription factors and microRNA156 in rice. Plant Physiol. 2006;142(1):280-93.

27. Wu G, Park MY, Conway SR, Wang JW, Weigel D, Poethig RS. The sequential action of miR156 and miR172 regulates developmental timing in Arabidopsis. Cell. 2009;138(4):750-9.

28. Nodine MD, Bartel DP. MicroRNAs prevent precocious gene expression and enable pattern formation during plant embryogenesis. Genes Dev. 2010; 24(23):2678-92.

29. Shikata M, Koyama T, Mitsuda N, Ohme-Takagi M. Arabidopsis SBP-box genes SPL10, SPL11 and SPL2 control morphological change in association with shoot maturation in the reproductive phase. Plant Cell Physiol. 2009: 50(12):2133-45.

30. Wang J, Czech B, Weigel D. miR156-regulated SPL transcription factors define an endogenous flowering pathway in Arabidopsis thaliana. Cell. 2009; 138(4):738-49.

31. Chuck GS, Tobias C, Sun L, Kraemer F, Li C, Dibble D, Arora R, Bragg JN, Vogel JP, Singh S. Overexpression of the maize Corngrass1 microRNA prevents flowering, improves digestibility, and increases starch content of switchgrass. Proc Natl Acad Sci. 2011;108(42):17550-5.

32. Willmann MR, Poethig RS. The effect of the floral repressor FLC on the timing and progression of vegetative phase change in Arabidopsis. Development. 2011;138(4):677-85.

33. Yang L, Conway SR, Poethig RS. Vegetative phase change is mediated by a leaf-derived signal that represses the transcription of miR156. Development. 2011;138(2):245-9.

34. Guo C, Xu Y, Shi M, Lai Y, Wu X, Wang H, Zhu Z, Poethig R, Wu G. Repression of miR156 by miR159 regulates the timing of the juvenile-toadult transition in Arabidopsis. Plant Cell. 2017:29:1293-304.

35. Fu C, Sunkar R, Zhou C, Hui S, Zhang J, Matts J, Wolf J, Mann DGJ, Stewart CN Jr, Tang $Y$, et al. Overexpression of miR156 in switchgrass (Panicum virgatum L.) results in various morphological alterations and leads to improved biomass production. Plant Biotechnol J. 2012;10(4):443-52.

36. Wang Q, Sun A, Chen S, Chen L, Guo F. SPL6 represses signalling outputs of ER stress in control of panicle cell death in rice. Nat Plants. 2018:4(5):280-8.

37. Shao $Y$, Zhou H, Wu Y, Zhang H, Lin J, Jiang X, He Q, Zhu J, Li Y, Yu H, Mao M. OsSPL3, an SBP-domain protein, regulates crown root development in rice. Plant Cell. 2019;31(6):1257-75.

38. Liu Q, Shen G, Peng K, Huang Z, Tong J, Kabir MH, Wang J, Zhang J, Qin G, Xiao $\mathrm{L}$. The alteration in the architecture of a T-DNA insertion rice mutant Osmtd1 is caused by upregulation of MicroRNA156f. J Integr Plant Biol. 2015; 57(10):819-29.

39. Jeong DH, Park S, Zhai J, Gurazada SGR, De Paoli E, Meyers BC, Green PJ. Massive analysis of rice small RNAs: mechanistic implications of regulated microRNAs and variants for differential target RNA cleavage. Plant Cell. 2011 23(12):4185-207.

40. Song X, Lu Z, Yu H, Shao G, Xiong J, Meng X, Jing Y, Liu G, Xiong G, Duan J, et al. IPA1 functions as a downstream transcription factor repressed by D53 in strigolactone signaling in rice. Cell Res. 2017;27(9):1128-41.

41. Harrell DL, Bond JA, Blanche S. Evaluation of main-crop stubble height on ratoon rice growth and development. Field Crops Res. 2009;114(3):396-403.

42. Yuan S, Cassman KG, Huang J, Peng S, Grassini P. Can ratoon cropping improve resource use efficiencies and profitability of rice in Central China? Field Crop Res. 2019;234:66-72.

43. Firouzi S, Aminpanah A. Rice single cropping or ratooning agro-system: which one is more environment-friendly? Environ SCI Pollut R. 2018;25(32):32246-56.

44. Faruq G, Taha $R$, Prodhan Z. Rice ratoon crop: a sustainable rice production system for tropical hill agriculture. Sustainability. 2014;6(9):5785-800.

45. Liu M, Shi Z, Zhang X, Wang M, Zhang L, Zheng K, Liu J, Hu X, Di C, Qian Q, He Z, Yang D. Inducible overexpression of ideal plant Architecture1 improves both yield and disease resistance in rice. Nature Plants. 2019;5(4): 389-400.
46. Sakamoto T, Morinaka Y, Ishiyama K, Kobayashi M, Itoh H, Kayano T, Iwahori S, Matsuoka M, Tanaka H. Genetic manipulation of gibberellin metabolism in transgenic rice. Nat Biotechnol. 2003;21(8):909.

47. Sakamoto T, Kobayashi M, Itoh H, Tagiri A, Kayano T, Tanaka H, Iwahori S, Matsuoka M. Expression of a Gibberellin 2-Oxidase gene around the shoot apex is related to phase transition in rice. Plant Physiol. 2001;125(3):1508-16.

48. Kaneko M, Itoh H, Ueguchi-Tanaka M, Ashikari M, Matsuoka M. The aamylase induction in endosperm during rice seed germination is caused by gibberellin synthesized in epithelium. Plant Physiol. 2002;128:1264-70.

49. Xing Y, Zhang Q. Genetic and molecular bases of rice yield. Annu Rev Plant Biol. 2010:61:421-42

50. Zhang L, Yu H, Ma B, Liu G, Wang J, Wang J, Gao R, Li J, Liu J, Xu J, et al. A natural tandem array alleviates epigenetic repression of IPA1 and leads to superior yielding rice. Nat Commun. 2017:8:14789.

51. Wang $H$, Wang $H$. The miR156/SPL module, a regulatory hub and versatile toolbox, gears up crops for enhanced agronomic traits. Mol Plant. 2015;8(5):677-88.

52. Hiei Y, Komari T. Agrobacterium-mediated transformation of rice using immature embryos or calli induced from mature seed. Nat Protoc. 2008;3(5): 824-34.

53. Varkonyi-Gasic E, Wu R, Wood M, Walton EF, Hellens RP. Protocol: a highly sensitive RT-PCR method for detection and quantification of microRNAs. Plant Methods. 2007;3(1):12

54. Liu H, Guo Z, Gu F, Ke S, Sun D, Dong S, Liu W, Huang M, Xiao W, Yang G, et al. 4-coumarate-CoA ligase-like gene OSAAE3 negatively mediates the rice blast resistance, floret development and lignin biosynthesis. Front Plant Sci. 2016;7:2041.

55. Clemensson-Lindell A. Triphenyltetrazolium chloride as an indicator of fineroot vitality and environmental stress in coniferous forest stands: applications and limitations. Plant Soil. 1994;159(2):297-300.

\section{Publisher's Note}

Springer Nature remains neutral with regard to jurisdictional claims in published maps and institutional affiliations.
Ready to submit your research? Choose BMC and benefit from:

- fast, convenient online submission

- thorough peer review by experienced researchers in your field

- rapid publication on acceptance

- support for research data, including large and complex data types

- gold Open Access which fosters wider collaboration and increased citations

- maximum visibility for your research: over $100 \mathrm{M}$ website views per year

At $\mathrm{BMC}$, research is always in progress.

Learn more biomedcentral.com/submissions 